\title{
PANDEMIA DO COVID-19 E O ENSINO DE ENGENHARIA: DESAFIO ENFRENTADO PELOS PROFESSORES
}

\author{
Ana Carolina V. P. Giovannetti - anagiovannetti@gmail.com \\ AAD Projetos Consultoria e Engenharia Ltda \\ Rua Conselheiro Laurindo, 809 - Centro. \\ 80060-100 - Curitiba - PR \\ Patricia Fontana - patriciaffontana@gmail.com \\ Centro Universitário Curitiba (UniCuritiba), Departamento de Engenharia Civil \\ R. Chile, 1678 - Rebouças. \\ 80220-181- Curitiba - PR
}

Eimi V.Suzuki - veri.suzuki@gmail.com

Curitiba - PR

Andrezza do E. S. Cucinelli - andrezzacucinelli@yahoo.com.br

Universidade do Estado do Rio de Janeiro, Faculdade de Ciências Médicas

Avenida 28 de setembro, 87 fundos, $3^{\circ}$ andar - Vila Isabel.

20551-030 - Rio de Janeiro - RJ

Amacin R. Moreira - amacinrm@utfpr.edu.br

Universidade Tecnológica Federal do Paraná, Departamento de Construção Civil

Rua Deputado Heitor Alencar Furtado, 5000.

81280-340 - Curitiba - PR

Resumo: A pandemia do coronavírus (COVID-19) ocasionou impactos significativos em diversos segmentos da sociedade, em particular na educação. A adoção de medidas não farmacológicas para mitigar os seus efeitos, uma vez que inexistem alternativas farmacológicas para a doença, exigiu que o sistema educacional, em sua maioria presencial, repentinamente se adequasse para o ensino on-line ou ensino remoto emergencial. Diante disso, e levando-se em consideração que não há previsão do término da adoção dessas medidas, este estudo transversal procurou, através de um formulário disponibilizado eletronicamente pelas redes sociais, identificar as principais dificuldades e percepções dos docentes de engenharia dentro desse contexto. Participaram 52 docentes, de ambos os sexos e de diferentes estados brasileiros, atuando tanto na rede privada quanto na rede pública de ensino. De uma maneira geral, e levando-se em consideração as limitações referentes a amostragem obtida neste trabalho, os resultados demonstraram um panorama de adaptação apropriada nas IES da rede privada localizadas nas regiões Sul e Sudeste do país.

Palavras-chave: COVID-19. Ensino de engenharia. Ensino remoto emergencial. 


\section{INTRODUÇÃ̃O}

As alterações impostas pelo isolamento social, em decorrência da pandemia de COVID19, estão provocando mudanças no ensino em todo o mundo e os professores estão tentando se adaptar. Portanto, identificar as principais dificuldades dos docentes frente a essas mudanças, se faz necessário.

A Organização Mundial de Saúde (OMS) foi informada, em dezembro de 2019, do surgimento de uma doença, de origem desconhecida, na cidade de Wuhan, localizada na província de Hubei, na China. Trata-se de uma síndrome respiratória aguda (SARS), cujo agente causador é um vírus, pertencente à família dos coronavírus, denominado SARS-CoV-2, ficando a doença conhecida como COVID-19. O potencial de transmissibilidade deste vírus permitiu que a doença se espalhasse rapidamente por vários países, até que em 11 de março de 2020, a OMS declarou a COVID-19 uma pandemia (ZHU et al. 2020).

No Brasil, o primeiro caso confirmado ocorreu em 26 de fevereiro de 2020, em São Paulo (CRODA et al. 2020). Atualmente é considerado o segundo país em número de casos confirmados (394.507) com registro de mais de 24.600 óbitos (BRASIL 2020a). O Ministério da Educação (MEC), publicou a portaria $\mathrm{n}^{0} 343$, de 17 de março (2020b) que autorizou a substituição das aulas presenciais por aulas em meio digital, como medida para cumprir a recomendação de isolamento social. Em 28 de abril de 2020, com a continuidade do período de isolamento social, foi aprovada pelo Conselho Nacional de Educação (CNE) orientações para as instituições de ensino superior, com a finalidade de auxiliar a continuidade do ensino respeitando as recomendações sanitárias estabelecidas pela pandemia. Desta forma, recomendou-se o ensino através de mídias digitais, a substituição de atividades presenciais, exceto nas áreas de saúde, principalmente no tocante aos estágios curriculares e/ou nas atividades laboratoriais que necessitam de ambientes adequados para sua realização (ABMES 2020).

Segundo Fernandes, Henn e Kist (2020) a modalidade de ensino a distância exige um planejamento prévio e metodologia adequada. A possibilidade de substituição do ensino presencial para o ensino remoto surpreendeu as instituições de ensino e os docentes, ambos despreparados para o cenário exigido. Portanto, a análise das dificuldades e desafios encontrados pelos professores de engenharia nesse cenário é necessária, para gerar reflexões que culminem na melhoria da qualidade do ensino durante esse período. Assim, esta pesquisa tem por objetivo fazer um levantamento das experiências enfrentadas pelos docentes de engenharia no Brasil, através de um questionário on-line. Para isso, será abordado o ensino remoto emergencial e, em seguida, as principais características que o professor que atua na modalidade precisa apresentar para alcançar êxito com seus alunos. Dando seguimento será descrito a metodologia da pesquisa e a elaboração do questionário utilizado, assim como os resultados obtidos e uma breve discussão sobre as implicações desses resultados na rotina dos professores de engenharia.

\section{O ENSINO REMOTO EMERGENCIAL}

Segundo Holges e colaboradores (2020) o ensino remoto emergencial é um ensino on-line que se caracteriza por ser temporário, em resposta a uma situação emergencial, aplicado por um curto período, em substituição ao ensino presencial. Possui uma grande diferença do ensino a distância, pois este requer tempo e planejamento para um desenvolvimento adequado, e aquele é implementado de maneira bem mais rápida. $\mathrm{O}$ curto prazo para a aplicação do ensino remoto 
nesta pandemia fez com que a qualidade dos cursos diminuísse, por isso devem ser aplicados apenas como uma solução de curto prazo (HOLGES et al., 2020).

Arruda (2020) cita a importância do ensino remoto emergencial no cenário atual, pois segundo o autor essa forma de ensino mantem o vínculo entre alunos, docentes e outros profissionais de ensino. $\mathrm{O}$ afastamento desses por um período prolongado pode acarretar grave perda na qualidade dos cursos, que seriam mais graves do que as perdas geradas pela rápida transição para o ensino remoto emergencial.

\section{O PAPEL DO PROFESSOR NO ENSINO ON-LINE}

As instituições de ensino devem ser capazes de fornecer a continuidade de ensino e de desenvolver nos docentes as habilidades necessárias para o ensino on-line, e tudo isso em um curto período de tempo e o suporte deve abranger todos os docentes, pois o apoio ao professor é um elemento essencial no ensino remoto emergencial (HOLGES et al., 2020).

Aulas realizadas de maneira remota exigem uma nova maneira de planejamento, desenvolvimento e avaliação. Oliveira, Corrêa e Morés (2020) citam o despreparo de professores a essa nova demanda, principalmente ao que se refere a adaptação às novas ferramentas digitais, utilizadas para o ensino on-line. Os autores ressaltam também a importância da formação dos docentes como solução para o déficit encontrado, e sugerem um espaço on-line onde seria possível a interação e troca de experiências entre os docentes que ministram disciplinas de maneira remota.

O aluno tem um papel importante na educação on-line, mas cabe ao docente desenvolver técnicas que os motivem para que não ocorra a desistência do curso. Então, as metodologias adotadas no ensino presencial podem fazer com que os alunos apenas memorizem o conteúdo, ao invés de instigar a participação e, ajudá-los a criar novos conhecimentos (SANTOS; LINHARES, 2018).

Outro ponto importante na hora de entender a relação entre docentes e a modalidade a distância é que há um grande preconceito por parte dos docentes, que consideram que a modalidade presencial é mais eficiente e tem uma estrutura de ensino mais completa que o EaD, tendo em vista que a maior parte dos docentes do ensino a distância teve uma formação presencial (CARNEIRO; MONTEIRO, 2018).

Dessa forma, destaca-se para o atual momento a importância do descrito no parecer do CNE de 28 de abril de 2020 de que as instituições de ensino superior devem "organizar um processo de capacitação de docentes para o aprendizado à distância ou não presencial".

\section{QUESTIONÁRIO DE PESQUISA}

Com a finalidade de obter informações sobre as dificuldades dos docentes com a migração repentina dos conteúdos presenciais para o formato digital e, estabelecer reflexões acerca da qualidade do ensino disponibilizado durante a pandemia de COVID-19, este grupo de trabalho elaborou um estudo descritivo transversal. A coleta de dados foi realizada prospectivamente, através do formulário on-line desenvolvido para este trabalho, sem identificação dos participantes. O formulário foi disponibilizado aos docentes dos cursos de engenharia e/ou arquitetura do país, através de e-mail e grupos nas redes sociais Instagram, Facebook e Whatsapp, no período de 29 de abril de 2020 a 3 de maio de 2020 . O questionário foi composto por 18 (dezoito) perguntas, sendo 8 (oito) delas para avaliar a importância das afirmações com 
pesos variando entre 1 (baixo) a 5 (alto), 4 (quatro) de múltipla escolha com resposta múltipla, 5 (cinco) questões de múltipla escolha e uma questão de resposta discursiva curta.

\section{ANÁLISE DOS RESULTADOS}

A pesquisa realizada teve um alcance de 52 profissionais da educação, em diferentes estados do país e campos de atuação, sendo 26 docentes no estado do Paraná, 7 de Minas Gerais, 6 de São Paulo, 3 de Santa Catarina, 2 de Pernambuco e 1 docente de cada um dos estados Piauí, Mato Grosso do Sul, Rio Grande do Sul e Ceará. Apenas 4 profissionais não informaram o estado em que leciona. Na figura 1 estão indicados os cursos nos quais os professores lecionam, sendo que um mesmo profissional pode atuar em mais de um curso.

Figura 1 - Cursos de atuação dos participantes.

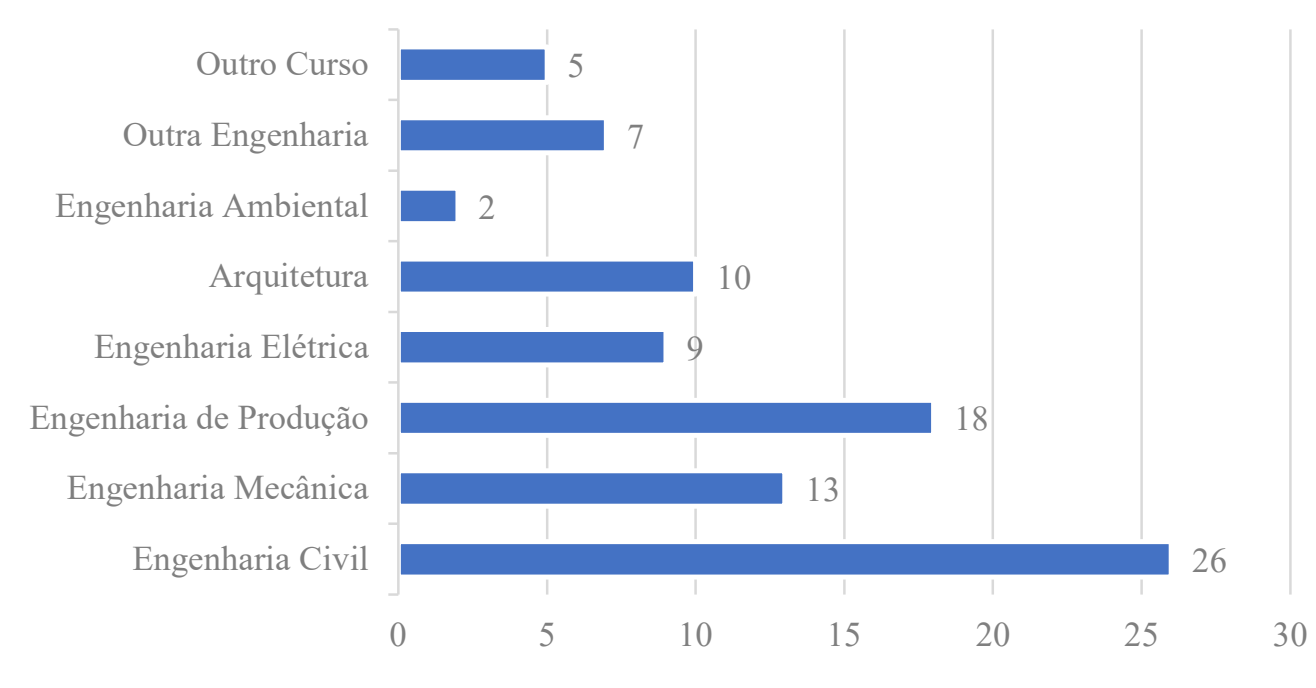

Fonte: Os autores.

Não estão lecionando, de maneira on-line, síncrona ou assíncrona, 5 profissionais em nenhuma das instituições de ensino que atuam, sendo 3 professores da rede pública, 1 professor da rede particular e 1 professor que leciona em instituições pertencentes as duas redes de ensino. Apenas 1 (um) informou que o ensino antes da quarentena era presencial/semipresencial. Dessa forma, foram excluídos da análise dos dados, aqueles que indicaram não ter tido contato com esse tipo de ensino, seja agora, seja no momento que antecedeu a pandemia, totalizando o número amostral de 48 profissionais neste estudo.

Do total de participantes, 45 lecionavam antes da quarentena em cursos presenciais, $2 \mathrm{em}$ cursos semipresenciais e 1 em curso a distância. Sobre o tipo de instituição, 40 profissionais lecionam em ensino particular, 5 em ensino público e 3 nos dois ensinos.

A experiência desses 48 profissionais no ensino a distância antes da quarentena é apresentada na Figura 2, onde 1 representa nenhuma experiência e 5 representa muita experiência, onde $73 \%$ (valores 1 e 2 na escala) dos participantes consideraram ter pouca ou nenhuma experiência nessa forma de ensino. 


\section{COBENGE (C) COBENCE 2020 da ABENGE}

\section{"Os desafios para formar hoje o engenheiro do amanhã"}

Figura 2 - Experiência com aulas on-line no período anterior a quarentena.

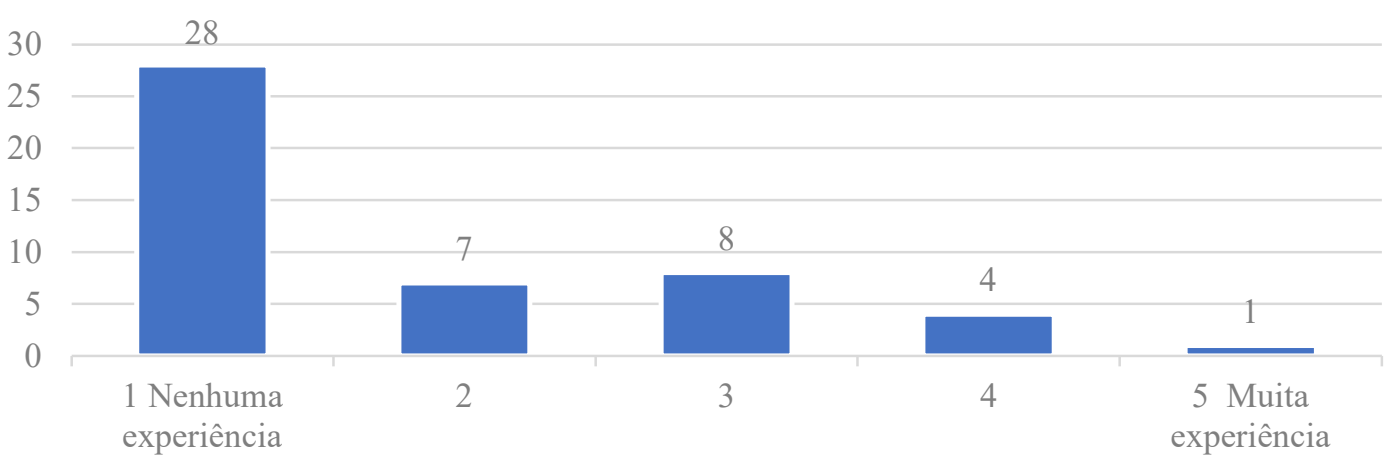

Fonte: Os autores.

Sobre o tempo de preparo das aulas on-line em relação ao ensino presencial (Figura 3), $71 \%$ dos profissionais responderam que o tempo é maior (respostas 4 e 5 na escala). Ainda, quando analisadas as principais dificuldades nessa modalidade de ensino (Figura 4), 63\% comentaram sobre o tempo de preparo das aulas e $44 \%$ comentaram sobre o tempo de correção de atividades.

Figura 3 - Tempo para preparo das aulas a distância em comparação com as presenciais.

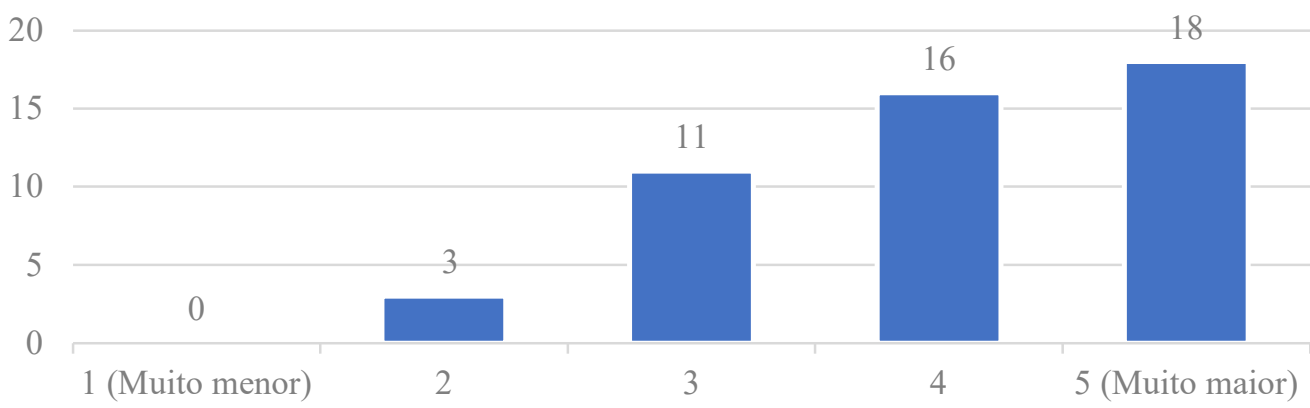

Fonte: Os autores.

Figura 4 - Principais dificuldades com as aulas a distância.

Falta de suporte ou definição da instituição

A dificuldade da realização de aulas práticas

Tempo de correção de atividades

Tempo de preparo de aula

Dificuldade com novos programas

Falta de equipamentos ou condições adequadas

Muitas distrações em casa ou falta de um ambiente

Falta do contato direto com o aluno

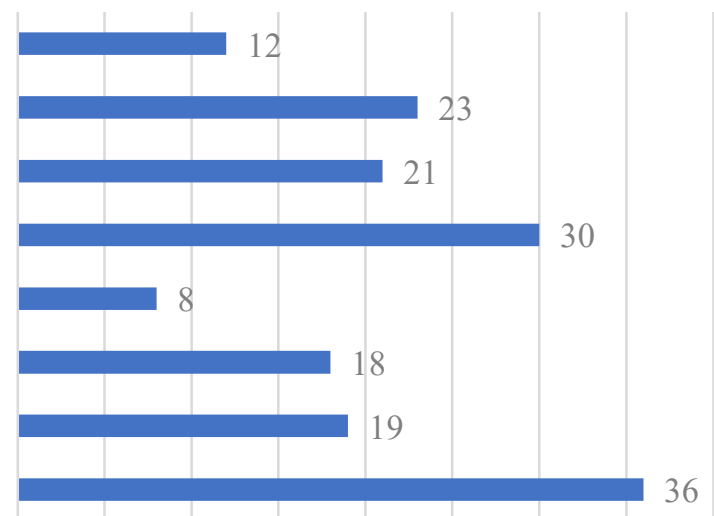

Fonte: Os autores. 
Analisando os resultados da pergunta sobre os meios de ensino (Figura 5), verifica-se que $88 \%$ dos professores realiza a postagem de conteúdo, o que indica a necessidade de tempo para produção desse conteúdo. Ainda, $77 \%$ realizam a postagem de lista de exercícios e $54 \%$ gravam vídeos para postagem aos alunos. Observa-se, então, que a maior parte dos entrevistados desenvolve materiais complementares para auxiliar no ensino, além do desenvolvimento da própria aula, que para $92 \%$ dos docentes acontece ao vivo com interação dos alunos. Dessa forma, confirma-se que os docentes requerem horas complementares de trabalho, a fim de atender às necessidades da docência com aulas a distância.

Dentre as outras dificuldades relatadas, destaca-se a disponibilidade de recursos, seja referente aos equipamentos, seja referente ao meio, sendo que entre $38 \%$ e $40 \%$ das respostas indicaram deficiência nessas questões, respectivamente. Os profissionais entrevistados relataram que a maior dificuldade está vinculada a falta de contato direto com o aluno para verificação de suas expressões ao longo da aula, problema esse inerente às atividades a distância.

Figura 5 - Principais recursos digitais utilizados.

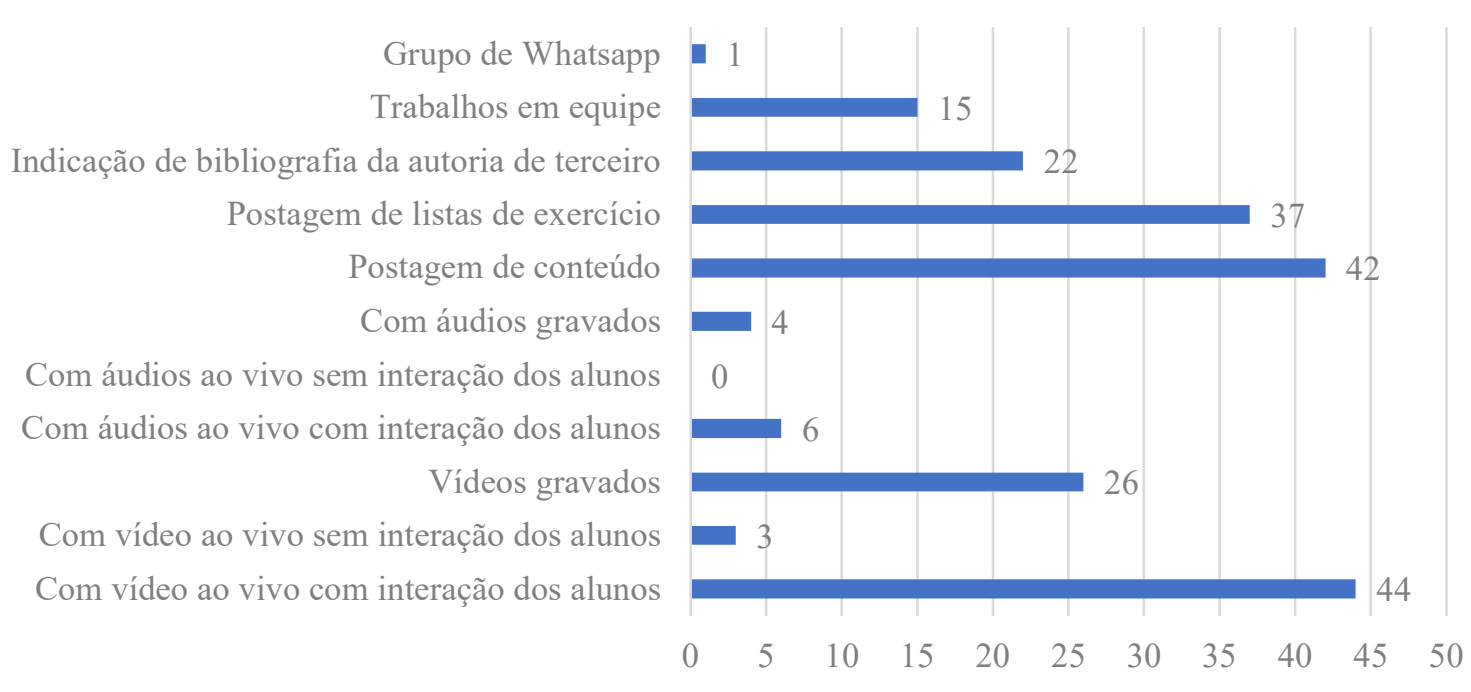

Fonte: Os autores.

Sobre o suporte da instituição de ensino no atual momento, apenas $25 \%$ dos profissionais relataram alguma dificuldade, o que indica que, apesar das dificuldades enfrentadas durante a pandemia do COVID-19, a maior parte das instituições aos quais os professores entrevistados fazem parte conseguiram contornar as dificuldades referentes à adaptação do ensino presencial para o ensino com atividades remotas (Figura 6).

$\mathrm{Na}$ mesma linha, os docentes entrevistados indicam, em sua maioria (67\%), que a instituição de ensino em que leciona apresenta preparo médio a muito bom para a modalidade de ensino a distância (Figura 7). Dentre aqueles que informaram falta de apoio da instituição consta que o relato de que a instituição não ministrou curso para os alunos aprenderem a usar as plataformas digitais, sobrecarregando o docente que além das atribuições que lhe são pertinentes teve que dar suporte aos alunos no aprendizado das novas tecnologias. 


\section{COBENGE CCOBENGE 2020}

\section{"Os desafios para formar hoje o engenheiro do amanhã"}

Figura 6 - Apoio da Instituição ao docente.

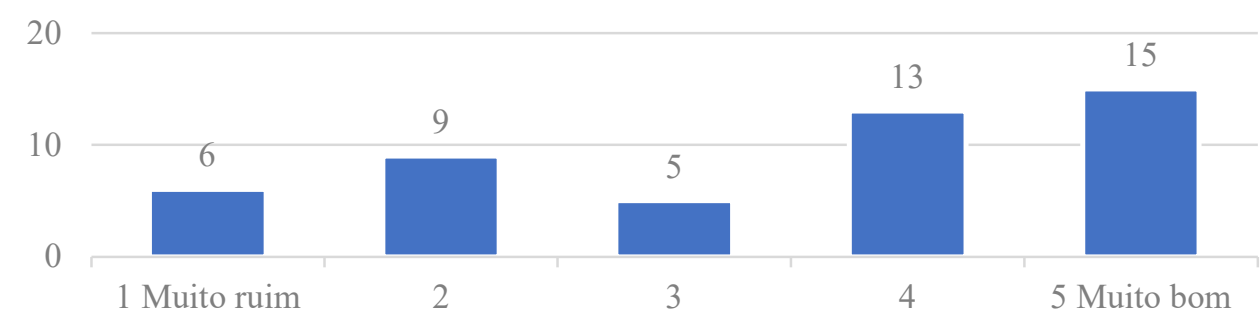

Fonte: Os autores.

Figura 7 - Preparo da instituição para o ensino a distância.

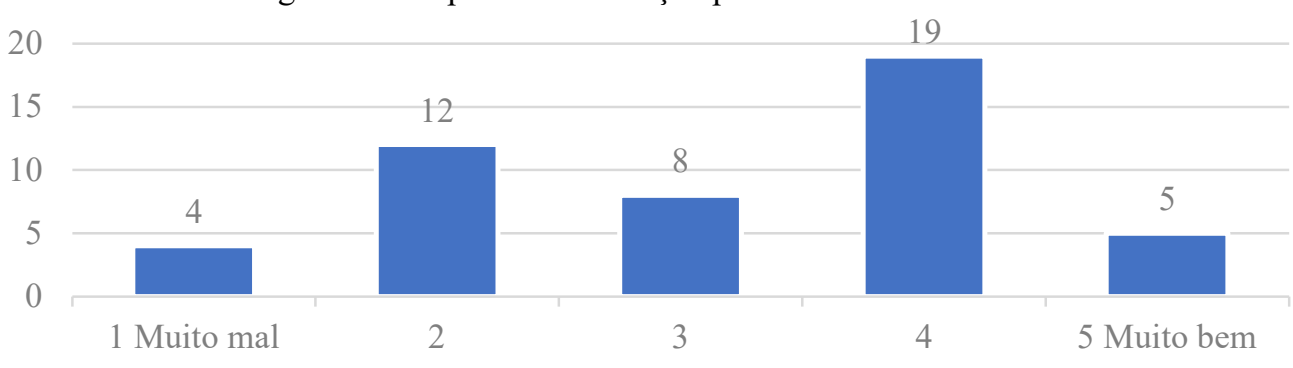

Fonte: Os autores.

Em relação ao desempenho do aluno, $40 \%$ dos docentes que responderam à pesquisa informaram que agora o aprendizado dos alunos no ambiente digital é pior ou muito pior que no caso de aulas presenciais, $52 \%$ responderam que é equivalente e apenas $8 \%$ responderam que é melhor ou muito melhor.

Esse resultado associa-se a outro dado coletado, no qual os entrevistados demonstraram que o preparo do aluno a esse tipo de ensino ainda é muito baixo. Na Figura 9 é possível observar que $71 \%$ dos professores informaram que os alunos estão mal ou muito mal preparados para essa modalidade de ensino. Ainda, $40 \%$ dos entrevistados acreditam que a aceitação pelos alunos a essa modalidade do ensino é ruim ou muito ruim, $46 \%$ acreditam ser mediana e somente $15 \%$ entendem ser boa (Figura 10 ).

Figura 8 - Aprendizado dos alunos com as aulas a distância.

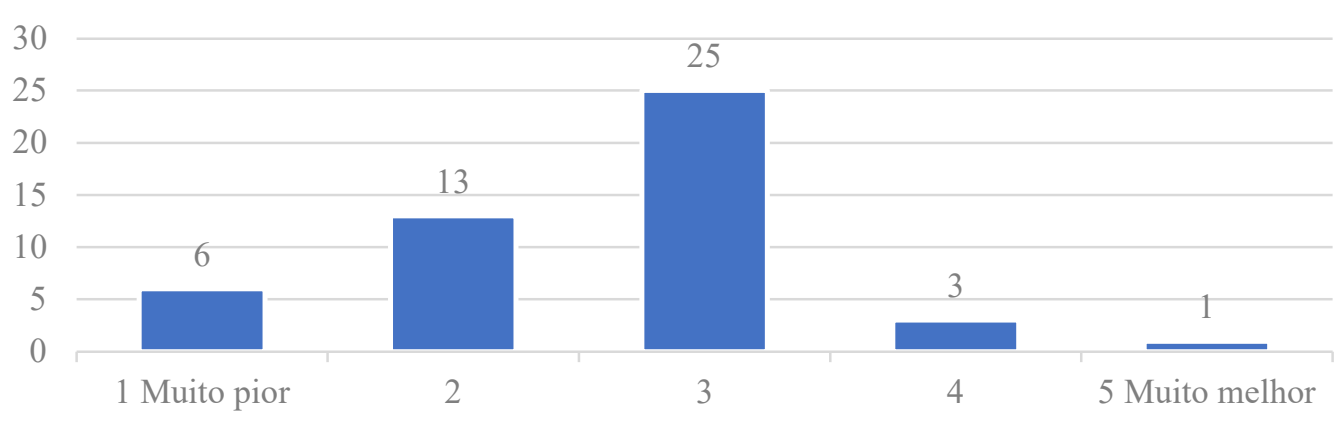

Fonte: Os autores. 
Figura 9 - Preparo dos alunos para a EaD.

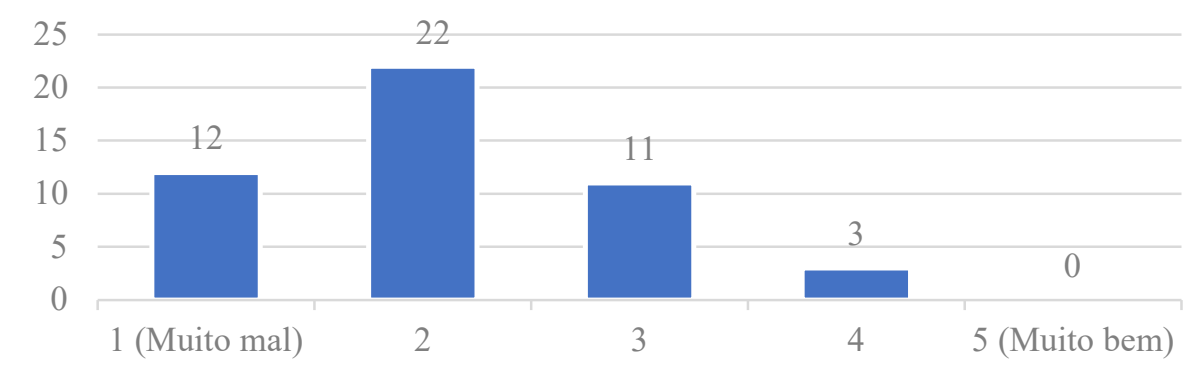

Fonte: Os autores.

Figura 10 - Aceitação dos alunos para a EaD.

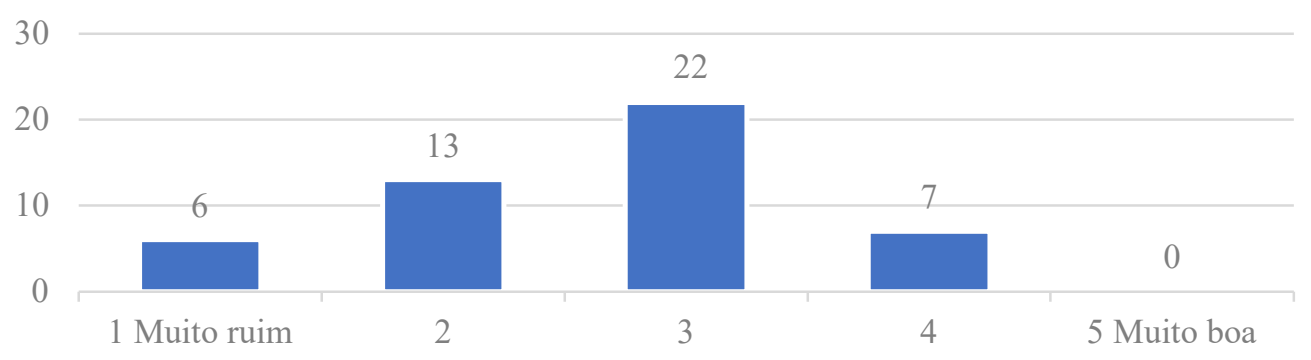

Fonte: Os autores.

Por fim, a percepção dos entrevistados com relação à preferência pela modalidade de ensino e com a experiência da docência através dos meios digitais indicaram que $71 \%$ preferem o ensino presencial, $21 \%$ o semipresencial e apenas $2 \%$, representando apenas 1 entrevistado, apresentou preferência pelo ensino a distância, enquanto $6 \%$ demonstraram ser indiferentes.

\section{CONSIDERAÇÕES FINAIS}

O alto potencial de transmissão do vírus SARS-CoV-2 elevou a doença COVID-19 a condição de pandemia. A ausência de medidas farmacológicas impôs a quarentena e o isolamento social como uma das principais medidas para mitigar a sua disseminação. De forma rápida, sem um planejamento adequado e sem a capacitação dos alunos, dos docentes e das próprias instituições educacionais ocorreu à migração do ensino presencial para um ensino online/remoto utilizando as mídias digitais. Estes termos são usados para diferenciar o que se preconiza como educação a distância, do ensino que se estabeleceu com a urgência imposta pela COVID-19.

Este trabalho demonstrou que a maioria dos docentes entrevistados pertence aos grandes centros urbanos das regiões Sul e Sudeste do país e que $89 \%$ destes atuam na rede particular de ensino. Diante desta amostragem, apenas 9,6\% dos participantes não estão lecionando de maneira remota durante a quarentena, indicando que um número representativo de instituições de ensino privadas promoveu/viabilizou o ensino remoto como alternativa para o cumprimento do calendário acadêmico. Apesar das dificuldades enfrentadas no momento, as IES da rede 
privada das regiões Sul e Sudeste do país apresentam meios que viabilizam o desenvolvimento de aulas síncronas com o uso das tecnologias digitais. No entanto, há o que se melhorar para os $32 \%$ insatisfeitos, ressaltando que a maioria destes leciona na rede pública de ensino.

Além disso, demonstrou que o desempenho do ensino com a aplicação de aulas a distância depende do suporte técnico dado pela instituição aos professores, o qual deve ocorrer através do fornecimento de equipamentos e espaço adequado, assim como, metodologias de ensino adequadas a esse formato. Este fato sugere à realização de pesquisas posteriores, com o objetivo de desenvolver políticas públicas que viabilizem o ensino remoto para a população mais carente, tanto ao nível de recursos oferecidos pelas IES, quanto aos recursos e capacitação da utilização das mídias digitais pelos docentes e alunos da rede pública de ensino.

Com os dados obtidos espera-se que as instituições de ensino possam se mobilizar para que sejam tomadas decisões assertivas a fim de elevar a qualidade do ensino com o uso de tecnologias digitais. Reitera-se que, diante da amostragem obtida, este trabalho não pretende extrapolar os dados para uma população maior, porém é um indicativo de que novos trabalhos devam ser elaborados, principalmente sob a ótica dos docentes que ministram suas aulas em IES da rede pública, com a finalidade de melhorar as condições de trabalho dos docentes dos cursos de engenharia e arquitetura.

\section{REFERÊNCIAS}

ABMES, Associação Brasileira de Mantenedoras de Ensino Superior. Aulas Remotas ou EAD? Disponível em: <https://abmes.org.br/noticias/detalhe/3705/aulas-remotas-ou-ead->. Acesso em: 8 maio 2020.

ARRUDA, Eucidio P. EDUCAÇÃO REMOTA EMERGENCIAL: elementos para políticas públicas na educação brasileira em tempos de Covid-19. Revista Educacional a Distância. Porto Alegre - RS, v. 7, n. 1, 2020.

BRASIL. Ministério da Educação. Brasil confirma primeiro caso da doença. Disponível em: < https://www.saude.gov.br/noticias/agencia-saude/46435-brasil-confirmaprimeiro-caso-de-novo-coronavirus $>$. Acesso em 02 abr. 2020a.

. Reorganização do Calendário Escolar e da possibilidade de cômputo de atividades não presenciais para fins de cumprimento da carga horária mínima anual, em razão da Pandemia da COVID-19. Brasília - DF. 2020 b.

. Portaria $\mathrm{N}^{\circ}$ 343, de 17 de março de 2020. Disponível em:

<http://www.in.gov.br/en/web/dou/-/portaria-n-343-de-17-de-marco-de-2020-248564376>. Acesso em 02 abr. 2020c.

. Portaria $\mathrm{N}^{\circ}$ 2.117, de 06 de dezembro de 2019. Disponível em:

$<$ http://www.in.gov.br/en/web/dou/-/portaria-n-2.117-de-6-de-dezembro-de-2019232670913>. Acesso em 02 abr. 2019.

CARNEIRO, David V.; MONTEIRO, Patrícia O. Representações sociais docentes: EaD e educação presencial. Revista EaD em Foco, v. 8, n. 1, jun., 2018. 
CRODA, Julio, et al. COVID-19 in Brazil: Advantages of a Socialized Unified Health System and Preparation to Contain Cases. Revista Da Sociedade Brasileira de Medicina Tropical v. 53, p. 2-7, 2020.

FERNANDES, Stéfani M.; HENN, Leonardo G.; KIST, Liane Batistela. O ensino a distância no Brasil: alguns apontamentos. Research, Society And Development. Itabira - MG, p. 6667. out. 2019.

HODGES, Charles et al. The difference between emergency remote teaching and online learning. EDUCAUSE Review. 27 mar. 2020.

OLIVEIRA, Raquel M.; CORRÊA, Ygor; MORÉS, Andréia. Ensino Remoto Emergencial em tempos de Covid-19: Formação docente e tecnologias digitais. Revista Internacional de Formação de Professores. Itapetininga - SP, v.5, p. 1-18, 2020.

SANTOS, Aryane R. A. dos; LINHARES, Danillo M. G. Reflexões sobre o papel do professor e do estudante na educação a distância. Cadernos Cajuína, v. 3, n. 1, p. 87 - 99, 2018 .

ZHU, Na, et al. A Novel Coronavirus from Patients with Pneumonia in China. New England Journal of Medicine v. 382, n. 8, p. 727-33, 2019.

\section{COVID-19 AND ENGINEERING TEACHING: CHALLENGE FACED BY TEACHERS}

Abstract: The coronavirus pandemic (COVID-19) has had significant impacts on different segments of society, particularly on the education. The adoption of non-pharmacological measures to mitigate its effects, demanded that the educational system suddenly had to adapted to remote teaching. Given this, and taking into account that there is no forecast for the end of the pandemic, this cross-sectional study used an electronically form sent by the social networks, to identify the main difficulties and perceptions of engineering professors within this context. Fifty-two professors from different Brazilian states answered the questions. These professors work in the private and public universities. In general, the results showed that the time required to prepare teaching activities has been too long and professors needs to prepare complementary materials. Professors responded that they miss the direct contact with the students and understand that student learning has been equal to or worse than it was, before the pandemic.

Keywords: COVID-19. Distance learning. Engineering teaching. EaD. Remote teaching 